\title{
The Effects of Legal System and Deregulation on FDI
}

\author{
Ali Mazyaki ${ }^{1}$ \\ Ehsan Moradi²
}

mazyaki@atu.ac.ir

\begin{abstract}
This study examines the effects of legal structure and deregulation on foreign direct investment (FDI). To do so, two categories of legal and economic variables have been examined. The data for the legal variables are extracted from the reports of Economic Freedom of the World, while the economic variables are collected from the database of the World Bank; also the panel covers the period 2000- 2014 for 89 countries. Economic variables in our empirical model include "net foreign direct investment per capita", "GDP per capita", "economic openness", "trade balance per capita", "growth rate of real GDP", and "real exchange rate"; and the legal variables consist of "legal structure and respect to property rights", "domestic deregulation", and "freedom to trade internationally". Our results indicate a direct, increasing, and augmentative effect from "independent legal structure and respect for property rights" on the ratio of foreign direct investment to gross domestic product.
\end{abstract}

Keywords: FDI, Legal System, Property Rights, Deregulation, Free Trade.

JEL Classification: O16, P33, P47.

1. Assistant Professor of Economics, Faculty of Economics, Allameh Tabataba'i University, Tehran, Iran (Corresponding Author).

2. M.A. in Socio-Economic System Engineering, Institute for Management and Planning Studies (IMPS), Tehran, Iran. 


\section{بررسى اثر ساختار حقوقى و مقرر اتزدايى بر

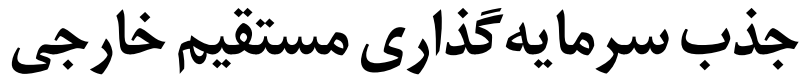

mazyaki@atu.ac.ir

على مزيكى استاديار اقتصاد دانشكده اقتصاد، دانشكاه علامه طباطبايی،تهران

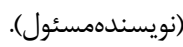

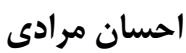

كارشناسىارشد مهيندسى سيستمهاى اقتصادى و اجتماعى، موسسه عالى آموزش و يزؤشش مديريت و برنامهر يزىى، تهران.

جـيده: با وجود يزوهشهاى فراوان در بررسى عوامل موثر بر جذب سرمايدگذارى خارجى، اثر

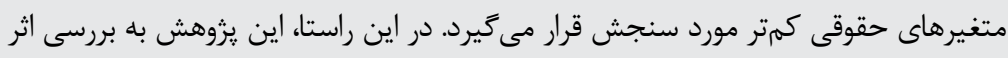

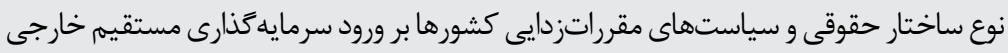

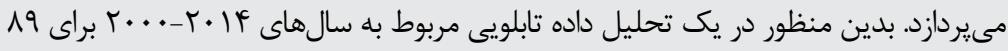

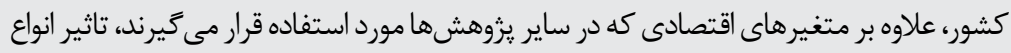

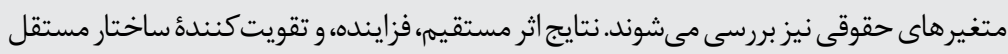

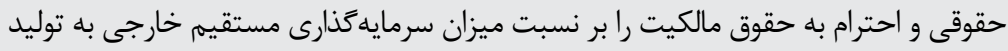
ناخالص داخلى تاييدمى كند.

كليدوازهها: سرمايهگذارى مستقيم خارجى، ساختار حقوقى، حقوق مالكيت، مقرراتزدايى، آزادى تجارت بين المللى. طبقدبندى O16, P33, P47 :JEL. 


\section{مقدمه}

با وجود اهميت بالاى سرمايهگذارى مستقيم خارجى و تاثير آن بر رشد اقتصادى و كمبود

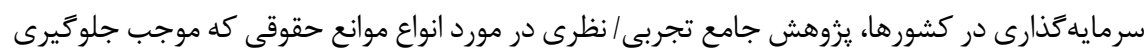

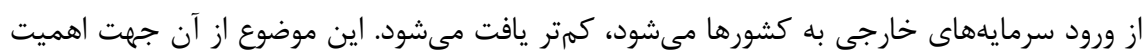

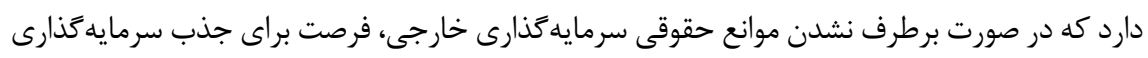

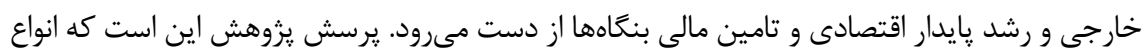
موانع حقوقى تا جه حد مانعى براى رشد سرمايهَذارى خارجى در كشورها محسوب مىشوند. دسترسى مارى

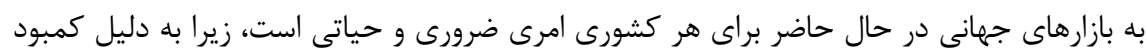

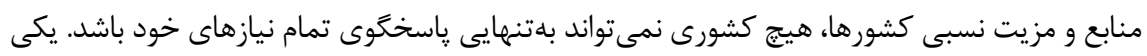

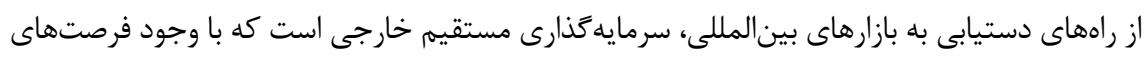

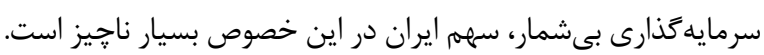

\section{مبانى نظرى بزوهش}

در نمودار (1)، نسبت سرمايهگذارى مستقيم خارجى به توليد ناخالص داخلى در كشورهاى

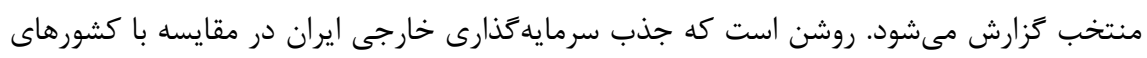

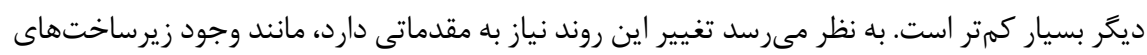

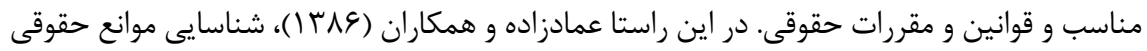

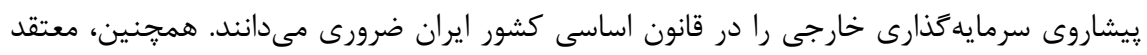

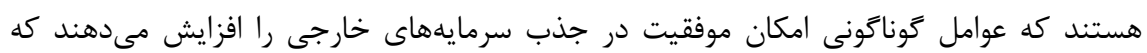

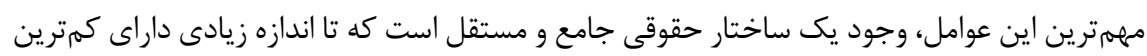

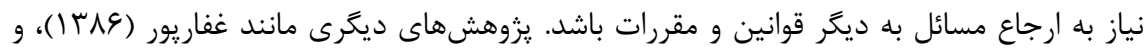

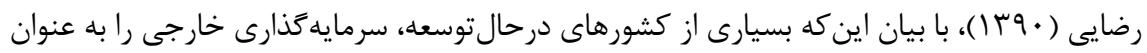

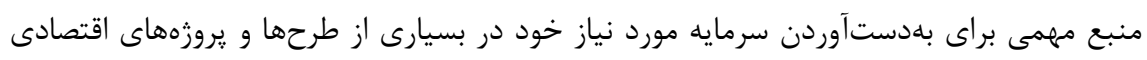

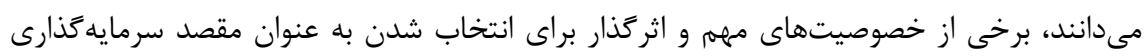

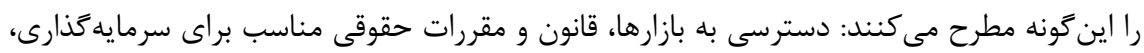

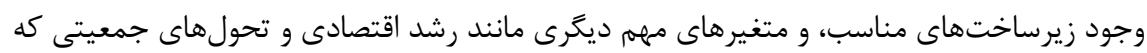

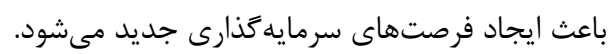




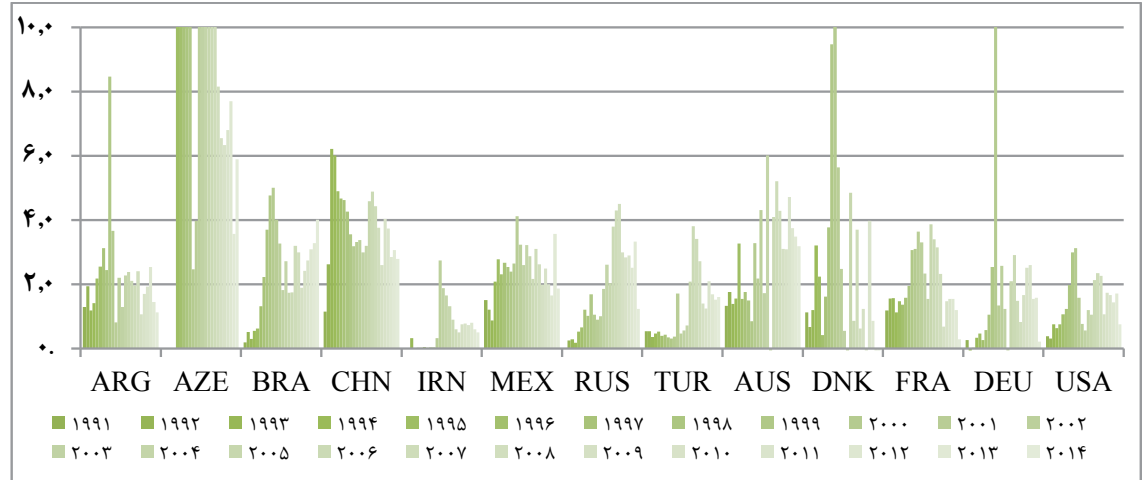

نمودار ا: مقايسه نسبت سرمايه حذارى مستقيم خارجى به توليد ناخالص داخلى در كشورهاى منتخب

در جدول (1)، به دليل گستردگى و تنوع ادبيات در ايران و خارج، يزوهشها بر اساس متغير و نوع اثر مشاهدهده طبقهبندى مى شوند. جدول ا: اثر عوامل موثر بر سرمايه كذارى مستقيم خارجى در بزوهشهاى بيشين

\begin{tabular}{|c|c|c|c|}
\hline بىاثر & اثر منفى & اثر مثبت & متغير \\
\hline & & 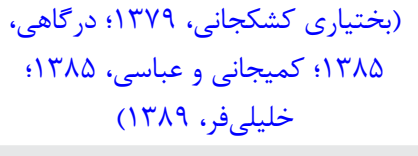 & $\begin{array}{l}\text { اندازه بازار } \\
\text { (GDP) }\end{array}$ \\
\hline \multirow[t]{2}{*}{$\begin{array}{c}\text { (Moosa \& } \\
\text { Cardak, 2006) }\end{array}$} & & 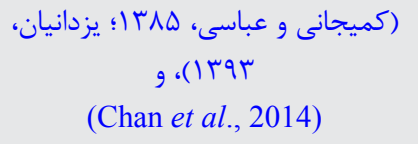 & رشد GDP \\
\hline & & 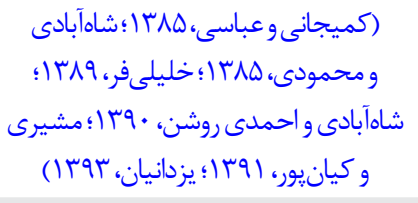 & بودن اقتصاد باز \\
\hline همكاران، (صمدى و و|) & 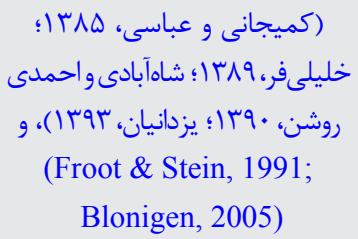 & 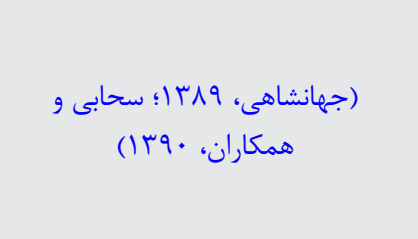 & نرخ ارز \\
\hline
\end{tabular}


ادامه جدول 1: اثر عوامل موثر بر سرمايه تذارى مستقيم خارجى در يخوهشهاى ييشين

\begin{tabular}{|c|c|c|c|}
\hline 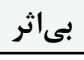 & اثر منفى & اثر مثبت & متغير \\
\hline & \multirow{8}{*}{ 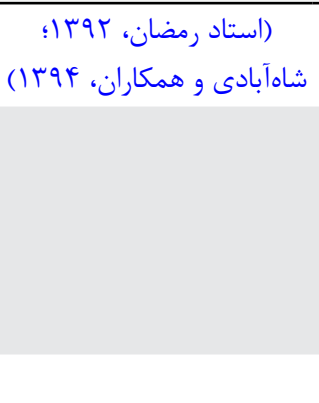 } & 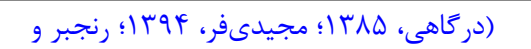 & آزادسازى \\
\hline & & 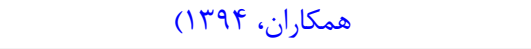 & اقتصادى \\
\hline & & (عمادز اده و همكاران، عیץ ا؛ مهدوى و برخوردارى، & \\
\hline & & 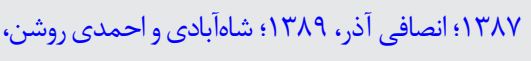 & \\
\hline & & 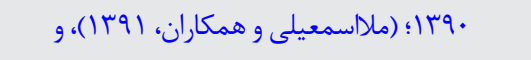 & 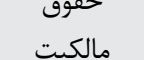 \\
\hline & & (Seyoum, 1996; Ushijima, 2013; Mathew \& & \\
\hline & & Mukherjee, 2014; Tanaka \& Iwaisako, 2014) & \\
\hline & & 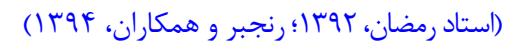 & مقرراتزدايى \\
\hline
\end{tabular}

روش رشناسى يزوهش

در اين بخش، ابتدا تعريف متغيرها سيس مدل و نتايج آن ارائه مىشود. بر اساس يزوهش هاى ييشين،

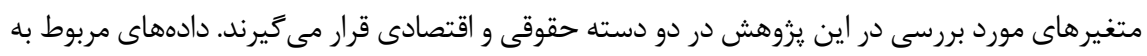

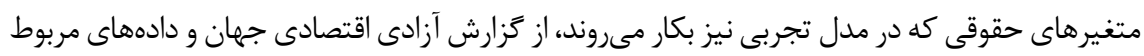
به متغيرهاى اقتصادى از ززارش بانك جهانى جمع آورى مىشوند. متغيرهاى اقتصادى مدل شامل سران سرانه

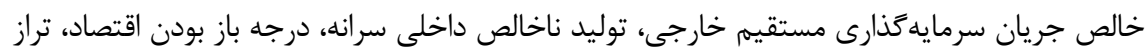
تجارى سرانه، نرخ رشد توليد ناخالص داخلى حقيقى، نرخ ارز حقيقى، و متغيرهاى حقوقى مدل شامل ساختار حقوقى و حقوق مالكيت، مقرراتزدايى در فضاى كسبوكار داخلى، و مقرراتزدايى براى تجارت

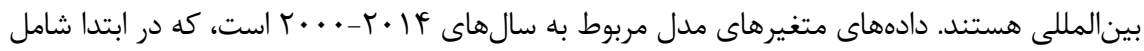

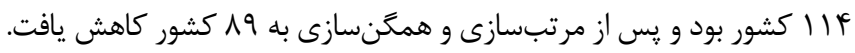

\section{متغيرهاى اقتصادى}

يزوهشهاى زيادى در مورد آثار متغيرهاى اقتصادى بر سرمايه گذارى مستقيم خارجى انجام شده

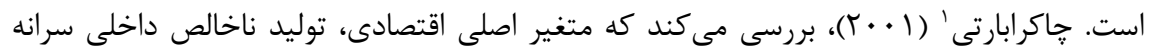
است و اثر آن را بر سرمايه كذارى مستقيم خارجى مثبت ارزيابى مى كند. باز بودن اقتصاد، كه بهطور 
معمول با نسبت مجموع صادرات به علاوه واردات تقسيم بر توليد ناخالص داخلى سنجيده مىشود،

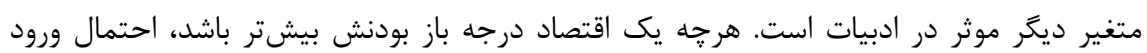

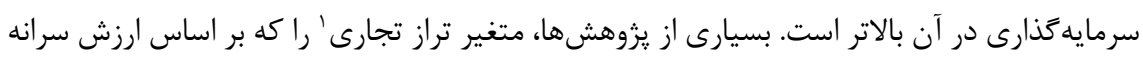

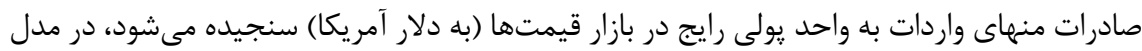

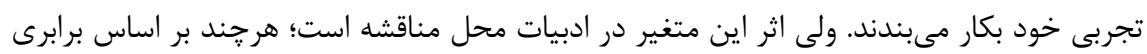

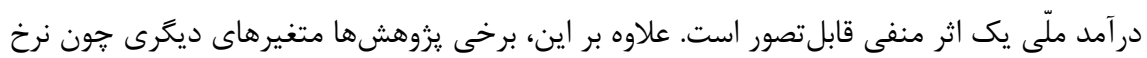

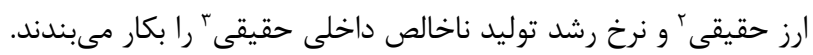

\section{متغيرهاى حقوقى}

بر اساس يزوهشهايى كه در مورد آثار متغيرهاى حقوقى بر سرمايه گذارى مستقيم خارجى انجام

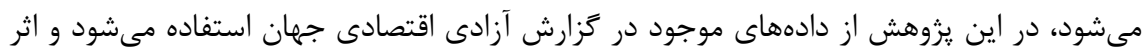

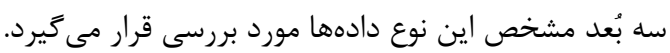

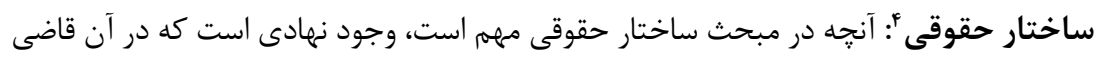

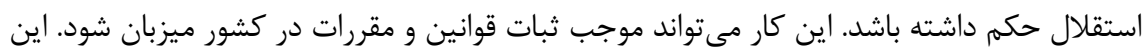

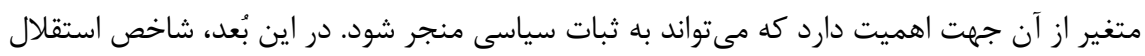
قضايى در نظركرفته مىشود. آنجه در حقوق مالكيت اهميت دارد اين است حقوق مالكيت تا جها

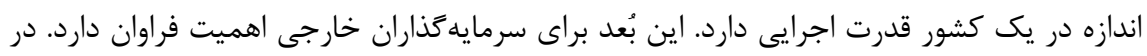

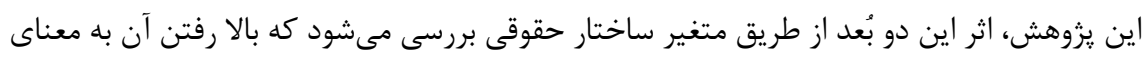
مستقلتر بودن دستخاه قضا و احترام به حقوق مالكيت است.

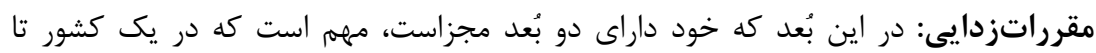

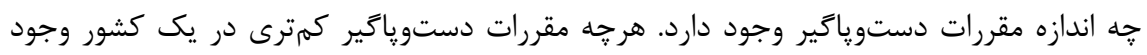

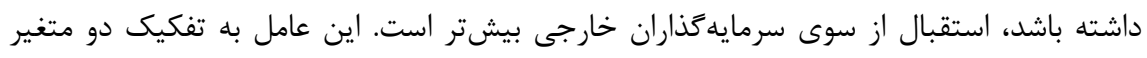

1. Trade Balance

2. Real Exchange Rate

اين نرخ براى يك كشور، بر اساس مقدار دلار ايالاتمتحده لازم براى رد و بدل يك واحد ارز محلى تعريف

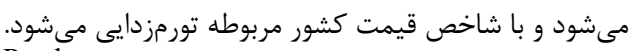


مقرراتزدايى در فضاى كسبو كار داخلى' و آزادى تجارت بينالمللى بدر نظرگرفته مىشود. اين دو متغير در حقيقت، مقرراتزدايى را در فضاى داخلى و فضاى بينالمللى مى مسنجند.

\section{مدل و نتايج}

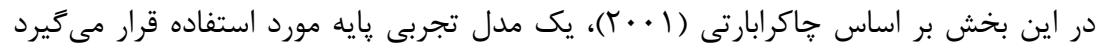
و متغيرهاى حقوقى به آن اضافه مىشوند. از آنجا كه در يزوهشهاى ييشين از دادههاى يك سال

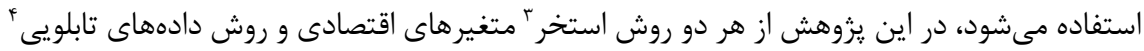

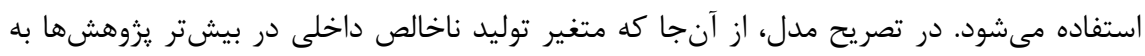

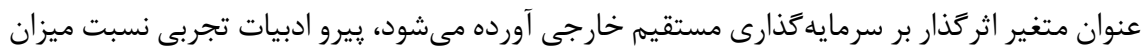

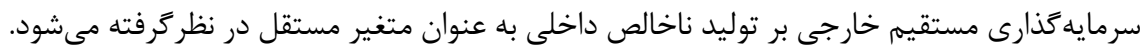

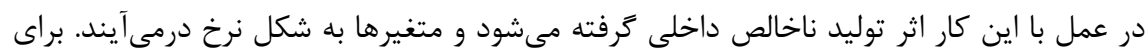

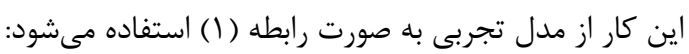

$\operatorname{fdigdp}_{i t}=\beta_{0}+\beta_{1} o p_{i t}+\beta_{3} n x g d p_{i t}+u_{i t}$

كه در آن

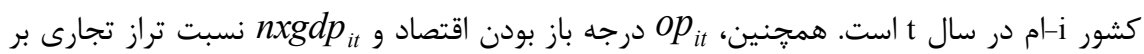
توليد ناخالص داخلى است. در ادامه، متغيرهاى حقوقى به شيوههاى متفاوتى به مدل پايهاى ( (1) اضافه

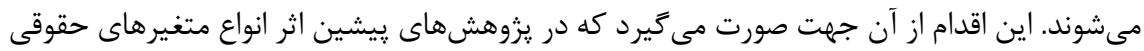

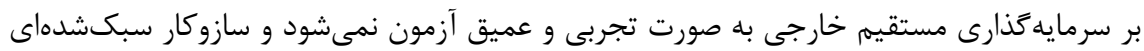

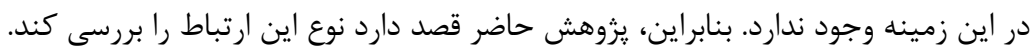

\section{اضافه كردن متغيرهاى حقوقى}

نتايج در اضافه كردن متغيرهاى حقوقى نشان مى دهند كه جون تغييرهاى اين متغيرها در طول زمان براى كشورها بسيار اندك هستند، استفاده از روش دادهاى تابلويى ممكن است مشكلزا باشد،

1. Deregulation

2. Freedom to Trade Internationally

3. Pooled Data

4. Panel Data 
קرا كه رابطه بسيار شديدى بين اثرهاى ثابت و اين متغيرهاى حقوقى وجود دارد. يس ممكن است

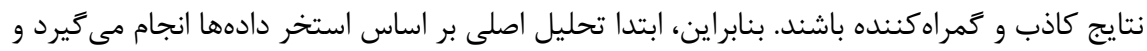
سيس براى اطمينان و رعايت احتياط، نتايج با دادههاى تابلويى بررسى مىشود.

جدول r: آمار توصيفى متغيرها

\begin{tabular}{|c|c|c|c|c|c|c|c|}
\hline بيشينه & كمينه & استاندارد انحراف & ميانگين & مشاهدهها & دام متغير & نام متغير در & متغير \\
\hline $1 / V^{F}$ & -.109 & .11 & $\cdot 11$ & $1 / 994$ & fdigd $_{i t}$ & FDIRGDPCO2005 & 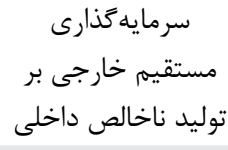 \\
\hline$f / D$ &.$/ 1 F$ & .19 & .19 & $1 / \Delta \Delta r$ & $o p_{i t}$ & OPR & درجه باز بودن اقتصاد \\
\hline .19 & $-T / \mathcal{F}$ & $\cdot / T$ & $-\cdot / \cdot 1$ & $1 / \Delta \Delta r$ & $n x g d p_{i t}$ & NXRGDPCO2005 & نسبت نراز تجارى بر \\
\hline $9 / 9$ & $1 / 4$ & $1 / 9$ & $\Delta / 9$ & I/DAT & $l s_{i t}$ & LS & ساختار حقوقى \\
\hline $1 / 9$ & س & $\cdot 19$ & $9 / 8$ & I/DAT & $D E R_{i t}$ & DER & مقرراتزدايى داخلى \\
\hline $9 / 7$ & . & $1 / 0$ & $\checkmark$ & I/DAT & $I N T D E R_{i t}$ & INTDER & زادى تجارت خارجى \\
\hline
\end{tabular}

در جدول (Y)، سه متغير حقوقى به مدل اضافه مىشوند كه هر سه معنادار هستند و اثر مثبتى بر نسبت سرمايهگذارى خارجى به توليد ناخالص داخلى دارند. علاوه بر اين، درجه باز بودن مدن اقتصاد

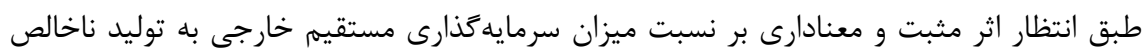

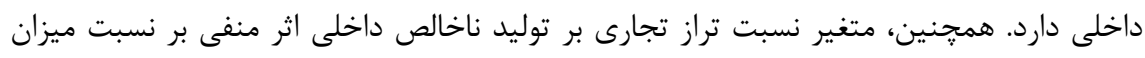

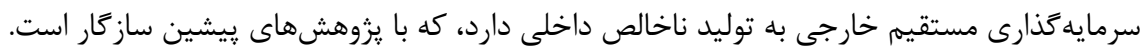

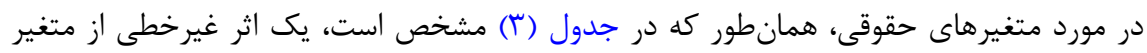

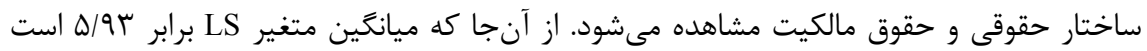
و رابطه درجه دو در 9•/ه كمينه مىشود، يس متوسط دنيا در بخش صعودى منحنى قرار دارد.

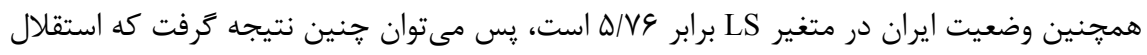

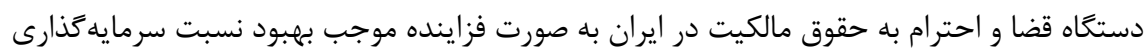


جدول rّ: نتايج تخمين مدل با استفاده از استخر متغيرهاى اقتصادى و اثر متغيرهاى حقوقى

\begin{tabular}{|c|c|c|c|c|}
\hline f & $r$ & $r$ & 1 & متغيرها \\
\hline$\cdot / \cdot \Delta 9^{* * w a n}$ & $\cdot / \cdot \Delta \xi^{* * * * m}$ & $\cdot / \cdot \Delta \varphi^{* * * *}$ & $\cdot / \cdot \Delta \Delta^{* * w^{*}}$ & OPR \\
\hline \multirow[t]{4}{*}{ 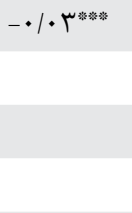 } & $-\cdot / \cdot T V^{*}$ & $-\cdot / \cdot \boldsymbol{Y}^{*}$ & $-\cdot / \cdot r^{*}$ 橉 & NXRGDPCO2005 \\
\hline & & $-\cdot 1 \cdot \cdot 19^{* * * * a}$ & 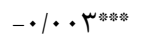 & LS \\
\hline & & $-\cdot|\cdot| 19^{* * *}$ & & LS2 \\
\hline & 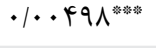 & & & DER \\
\hline$\cdot 1 \cdot \cdot 9^{* * w}$ & & & & INTDER \\
\hline$-\cdot / \cdot \boldsymbol{q r}^{\mathrm{s}}$ & $-\cdot / \cdot r V^{*}$ & $\cdot / \cdot Y \Lambda^{* * *}$ & $-\cdot|\cdot r|^{* w^{*} w^{*}}$ & Constant \\
\hline I/TFE & I/YFE & I/TFE & I/FFE & Observations \\
\hline$\cdot / r \wedge \Lambda$ & $\cdot / r \wedge \mid$ & ( & •/rNK & R-Squared \\
\hline
\end{tabular}

$$
\text { p }<0.01, * * \mathrm{p}<0.05, * \mathrm{p}<0.1 * * *: \text { توضيح }
$$

البته يرسشى كه مطرح مىشود اين است كه آيا اثر ابعاد مختلف حقوقى به يكديكر نيز وابسته

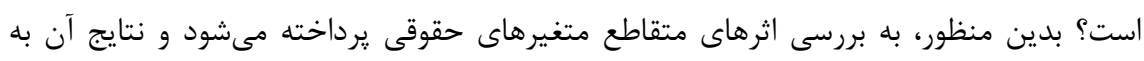

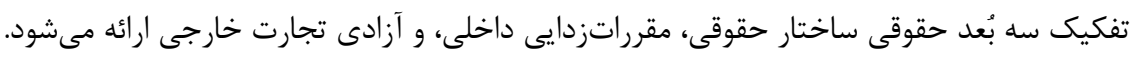

\section{ساختار حقوقى و حقوق مالكيت}

همانطور كه در جدول (f) مشاهده مىشود، در ستون نخست متغير ساختار حقوقى و حقوق مالكيت به مدل اضافه مىشوند. در اين حالت متغيرهاى درجه باز بودن اقتصاد، متغير نسبت تراز تجارى بر توليد ناخالص داخلى، و متغير ساختار حقوقى هر سه در سطح 99 درصد معنادار هستند و بلهترتيب اثر مثبت، منفى، و مثبتى بر نسبت ميزان سرمايهگذارى مستقيم خارجى به توليد ناخالص داخلى دارند. در حالت

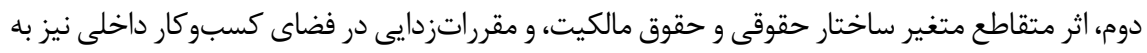
مدل اضافه مىشود. در اين حالت، همجنان متغيرهاى درجه باز بودن اقتصاد و متغير نسبت تراز تجارى معاري

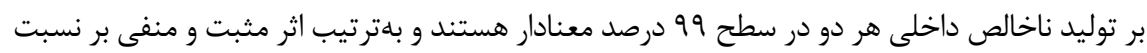

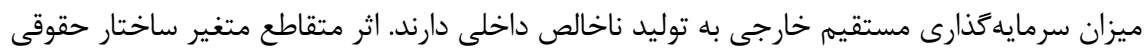

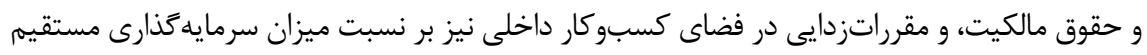

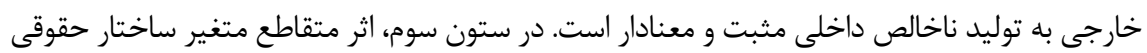


و حقوق مالكيت، و آزادى تجارت بينالمللى به مدل اضافه مىشود. در اين حالت، همجنان هر دو متغير درجه باز بودن اقتصاد و نسبت تراز تجارى به توليد ناخالص داخلى در سطح 99 درصد معنادار هستند. اثر متقاطع متغير ساختار حقوقى و حقوق مالكيت، و مقرراتزدايى براى تجارت بينالمللى نيز بر نسبت ميزان سرمايه گذارى مستقيم خارجى به توليد ناخالص داخلى مثبت و معنادار است.

\section{جدول †: نتايج تخمين مدل با استفاده از استخر متغيرهاى اقتصادى در بروسى اثر متغير ساختار حقوقى}

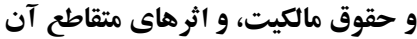

\begin{tabular}{|c|c|c|c|}
\hline$r$ & $r$ & 1 & متغيرها \\
\hline 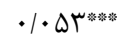 & 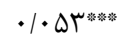 & 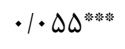 & OPR \\
\hline$-\cdot 1 \cdot r \Delta^{* * * \%}$ & $-\cdot / \cdot r^{w}$ & 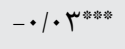 & NXRGDPCO2005 \\
\hline \multirow[t]{2}{*}{ 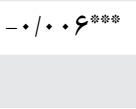 } & $-\cdot 1 \cdot \cdot r$ & 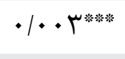 & $\mathrm{LS}$ \\
\hline & $\cdot 1 \cdot \cdot 1^{\text {米綵 }}$ & & LSDER \\
\hline 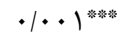 & & & LSINTDER \\
\hline$-\cdot 1 \cdot \wedge^{*}$ & $-\cdot 1 \cdot \mid f^{* * *}$ & $-\cdot 1 \cdot r^{\text {* }}$ & Constant \\
\hline I/THE & $1 /$ TYG & $1 / T F G$ & Observations \\
\hline$\cdot / r q 4$ & $\cdot / r \wedge \Delta$ & $\cdot \ln$ & R-Squared \\
\hline
\end{tabular}

از بررسى اثرهاى متقاطع بر اساس جدول (I) نتيجه مىشود كه اثر متغير ساختار حقوقى و مالكيت در مجموع مثبت و معنادار است، اما تا حد زيادى نيز به ميزان مقرراتزدايى بستكى دارد. $\frac{\partial f d i g d p}{\partial l s}=-0.0024+0.0006^{* * *} \times \overline{D E R}>0$

$\frac{\partial f d i g d p}{\partial l s}=-0.006^{* * *}+0.001^{* * *} \times \overline{I N T D E R}>0$

اين نتيجه را نشان مى دهد كه جنانجه مقرراتزدايى در فضاى داخلى يا بينالمللى صورت نخيرد،

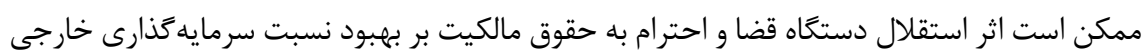
به توليد ناخالص داخلى محدود شود. به بيان ديخر، منفى بودن اثر متغير ساختار حقوقى در كنار اثر مثبت متقاطع بيانكر اين موضوع است كه مقرراتزدايى مىتواند موجب موثرتر شدن استقلال دستخاه قضا و احترام به حقوق مالكيت بر جذب سرمايهَذارى خارجى شود. 


\section{مقرراتزدايى در فضاى كسبوكار داخلى}

همانطور كه در جدول (ه) مشاهده مىشود، در ستون نخست متغير مقرراتزدايى در فضاى

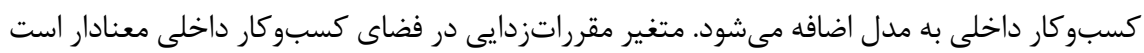
و اثر مثبتى بر نسبت ميزان سرمايهگذارى مستقيم خارجى بر توليد ناخالص داخلى دارد. در ستون دوم، اثر متقاطع متغير ساختار حقوقى و حقوق مالكيت، و در ستون سوم اثر متقاطع متغير آزادى مئى تجارت خارجى نيز به مدل اضافه مىشوند.

جدول ه: نتايج تخمين مدل با استفاده از استخر متغيرهاى اقتصادى و اضافه كردن متغير مقرراتزدايى

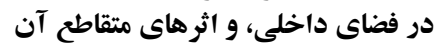

\begin{tabular}{|c|c|c|c|}
\hline r & r & 1 & متغير ها \\
\hline$\cdot / \cdot \Delta \Gamma^{\mu}$ & $\cdot / \cdot \Delta Y^{*}$ & $\cdot / \cdot \Delta Y^{*}$ & OPR \\
\hline 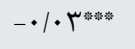 & 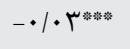 & 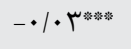 & NXRGDPCO2005 \\
\hline$-\cdot \mid \cdot \cdot \varphi^{\text {絭 }}$ & $\cdot 1 \cdot \cdot 1$ & 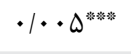 & DER \\
\hline & 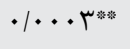 & & DERLS \\
\hline 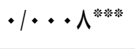 & & & DERINTDER \\
\hline$-\left.\cdot 1 \cdot 1\right|^{\mathrm{*} *}$ & 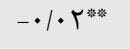 & $-\cdot 1 \cdot \boldsymbol{r}^{*}$ & Constant \\
\hline I/TFG & I/TFG & $1 / T+G$ & Observations \\
\hline$\cdot / 4 q$. & $\cdot / T \wedge D$ & $\cdot / 4 \wedge I$ & R-Squared \\
\hline
\end{tabular}

p $10.01, * * \mathrm{p}<0.05, * \mathrm{p}<0.1 * * *$

اثر متقاطع متغير ساختار حقوقى و آزادى تجارت بينالمللى مثبت و معنادار است. اين موضوع نشان مى دهد كه اثر متغير مقرراتزدايى در فضاى كسبوكار داخلى وابسته به ميزان مقرراتزدايى در فضاى

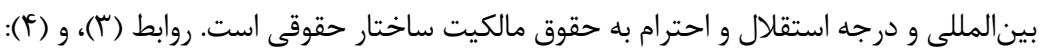

$\frac{\partial f d i g d p}{\partial D E R}=0.0006+0.0003^{* * *} \times \overline{l s}>0$

$\frac{\partial f d i g d p}{\partial D E R}=-0.004^{* * *}+0.0008^{* * *} \times \overline{I N T D E R}>0$

نشان مىدهند كه جنانجه مقرراتزدايى در فضاى بينالمللى صورت گيرد، اثر مقرراتزدايى در 
فضاى داخلى بر سرمايهَّارى مستقيم خارجى وجود دارد، اما در حالت مقابل جنين رخ نمى دهد.

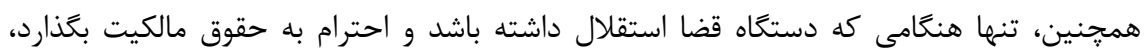
مقرراتزدايى در فضاى كسبوكار داخلى نيز بر كسترش ورود سرمايهذارى خارجى موثر است.

در ستون نخست جدول (9)، متغير آزادى تجارت بينالمللى اثر مثبت و معنادارى بر نسبت ميزان سرمايهگذارى مستقيم خارجى به توليد ناخالص داخلى دارد. در ستون دوم، اثر متقاطع متغير

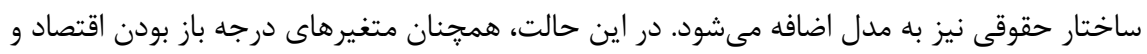

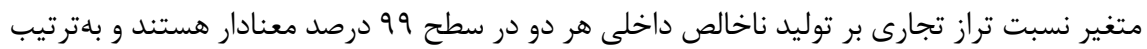

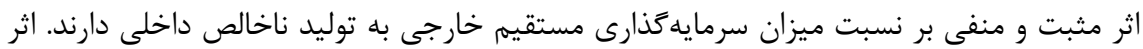

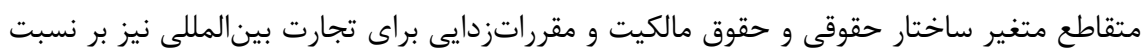

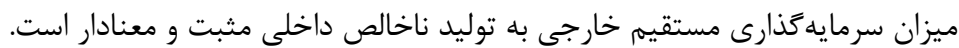

جدول و: نتايج تخمين مدل با استفاده از استخر متغيرهاى اقتصادى و اثر متغير مقرراتزدايي در فضاى

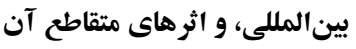

\begin{tabular}{|c|c|c|c|}
\hline$r$ & r & 1 & متغير ها \\
\hline$\cdot / \cdot \Delta r^{* * * * * a *}$ & $\cdot / \cdot \Delta \Delta^{* * a}$ & $\cdot / \cdot \Delta Y^{* * * * *}$ & OPR \\
\hline$-\cdot / \cdot$ 个絭粋 & 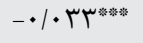 & 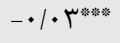 & NXRGDPCO2005 \\
\hline \multirow[t]{2}{*}{$\cdot 1 \cdot \cdot r$} & 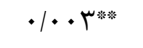 & 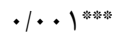 & INTDER \\
\hline & $\cdot \cdots r^{*}$ & & INTDERLS \\
\hline$\cdot / \cdots r *$ & & & INTDER DER \\
\hline 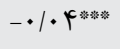 & 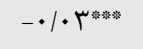 & 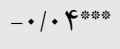 & \\
\hline I/TFE & $1 / T+4$ & I/TFE & Observations \\
\hline$\cdot / r \wedge 9$ & $\cdot / 4 q$. & $\cdot / \mathrm{TA \Lambda}$ & R-squared \\
\hline
\end{tabular}

p $<0.01, * * \mathrm{p}<0.05, * \mathrm{p}<0.1 * * *$ توضيح

در ستون سوم جدول (9)، نيز اثر متقاطع متغير مقرراتزدايى در فضاى كسبوكار داخلى و 
كسبو كار داخلى نيز بر نسبت ميزان سرمايهگذارى مستقيم خارجى به توليد ناخالص داخلى مثبت

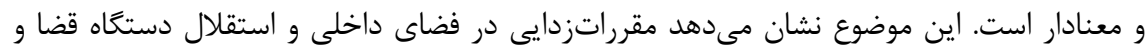

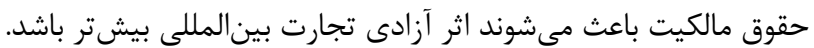

\section{بررسى نتايج با دادههاى تابلويى}

براى اطمينان از يافتههاى بهدستآمده، نتايج با استفاده از روش تابلويى اثرهاى تصادفى برآورد مىشوند. همانطور كه در جدول (V) مشاهده مىشود، معنادارى و علامت نتايج در اغلب موارد با باليا

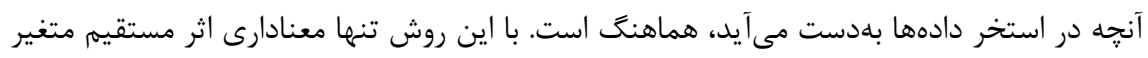
مقرراتزدايى در فضاى كسبوكار داخلى از بين مىرود. يس در نتيجه گيرى نهايى تنها به مواردى استناد مىشود كه در تمام روشها نتيجه يكسانى بروز مى دهند.

\begin{tabular}{|c|c|c|c|c|c|c|c|c|}
\hline$\Lambda$ & V & 9 & $\Delta$ & p & $r$ & $r$ & 1 & متغير ها \\
\hline 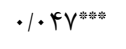 & 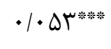 & 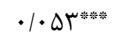 & $\cdot 1 \cdot x 9^{\text {絭䓪 }}$ & 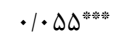 & 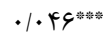 & 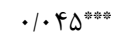 & $\cdot / \cdot p f^{\text {絭䓪 }}$ & OPR \\
\hline \multirow[t]{4}{*}{$-\cdot / \cdot \Lambda r^{\text {mats }}$} & $-\cdot 1 \cdot 9^{* m}$ & $-\cdot 1 \cdot 9 \Upsilon^{\mu * * * 3}$ & $-\cdot \mid \cdot 1)^{* * w^{* a}}$ & $-\cdot / \cdot \Delta 9^{* \omega * \ldots}$ & $-\cdot 1 \cdot 9^{* * * \ldots}$ & $-\cdot \mid \cdot 11^{\cdots * \ldots}$ & 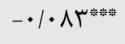 & NXRGDPCO2005 \\
\hline & & & $.1 \cdot 9$ & & & $-\cdot|\cdot r|^{*}$ & 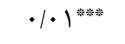 & LS \\
\hline & & & & & & $\cdot / \cdot r^{\text {絭 }}$ & & LS2 \\
\hline & $-\cdot 1 \cdot \cdot f$ & $-\cdot \cdot \cdot F f$ & & & $\cdot 1 \cdot \cdot 11$ & & & DER \\
\hline$-\cdot 1 \cdot \cdot \Lambda^{*}$ & & & & 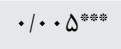 & & & & INTDER \\
\hline \multirow[t]{3}{*}{ 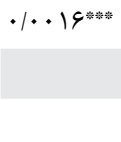 } & & & $\cdot 1 \cdot \cdots$ & & & & & LSINTDER \\
\hline & & $\cdot / \cdot \cdot V^{* * m}$ & & & & & & LSDER \\
\hline & $\cdot 1 \cdots V q$ & & & & & & & DERINTDER \\
\hline$-\cdot \cdot \cdot 1$ & $-\cdot 1 \cdot 1$ & $-\cdot 1 \cdot \cdot \Delta$ & $-\cdot 1 \cdot 9^{\text {券券 }}$ & $-\cdot / \cdot$ 卜 $^{\text {尊 }}$ & $-\cdot / \cdot r$ & $\cdot / \cdot r$ & $-\cdot 1 \cdot 9^{* * * 0}$ & Constant \\
\hline $1 / T+4$ & $1 / T+4$ & $1 / T r G$ & I/TFE & $1 / T+4$ & $1 / T+4$ & $1 / T+4$ & $1 / T+4$ & Observations \\
\hline 19 & 19 & 19 & $\wedge 9$ & 19 & 19 & 19 & 19 & Number of Country \\
\hline
\end{tabular}




\section{بحث و نتيجه كيرى}

در اين يزوهش، به بررسى اثر انواع متغيرهاى حقوقى بر ميزان سرمايهَذارى مستقيم خارجى

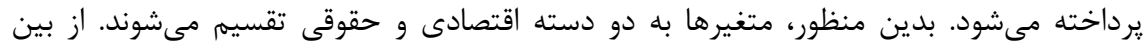

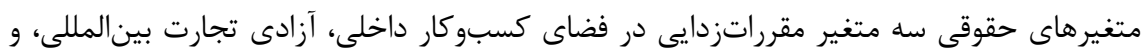
ساختار حقوقى شامل استقلال دستخاه قضا و احترام به حقوق مالكيت قرار دارند.

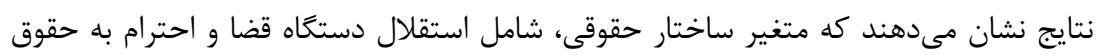

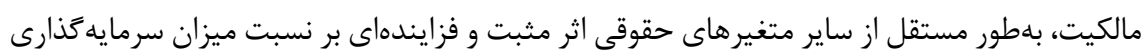

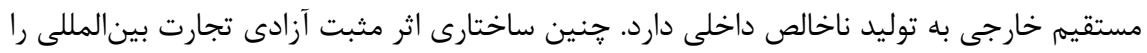

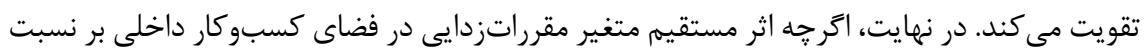

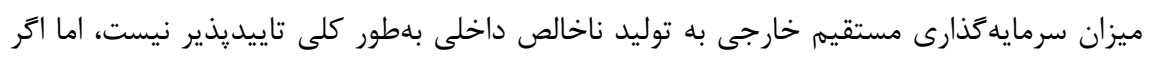

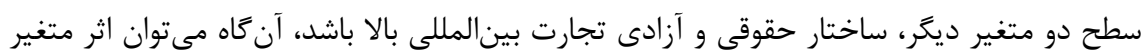

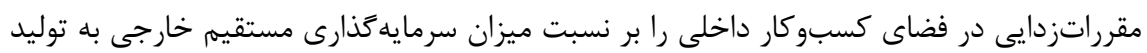

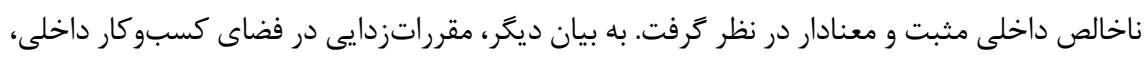

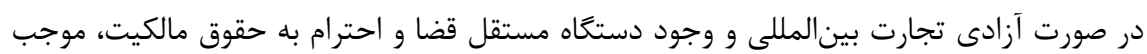
رشد سرمايه گذارى مستقيم خارجى ميشود. اين نتايج اهميت استقلال دستخاه قضا و احترام به حقوق مالكيت را به صورت تجربى نشان مى دهد و بيان مى كند شايد اهميت ساختار حقوقى مستقل و احترام

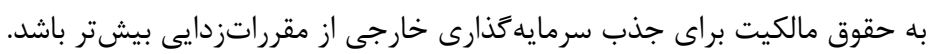

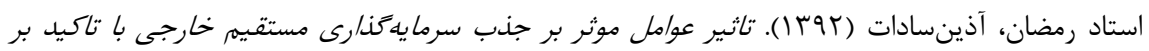

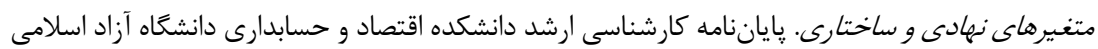
واحد تهران مركزى.

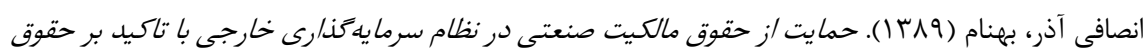

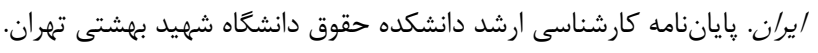


موثر بر جذب آن. پاياننامه كارشناسى ارشد موسسه عالى يزوهش در برنامهريزى و توسعه.

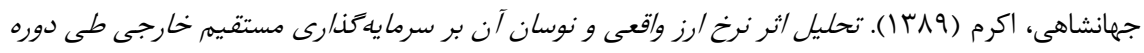

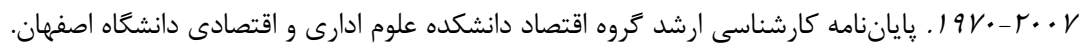

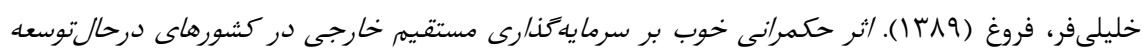

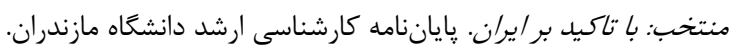

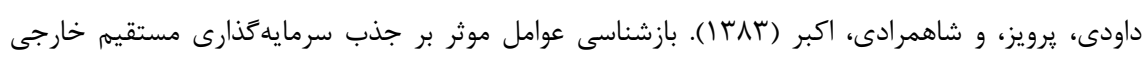

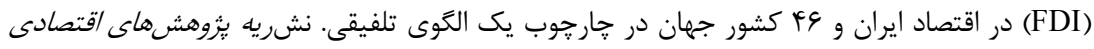

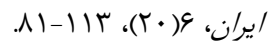

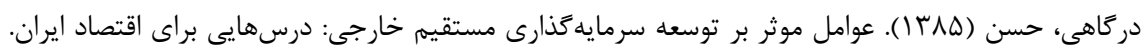

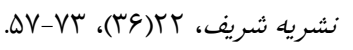

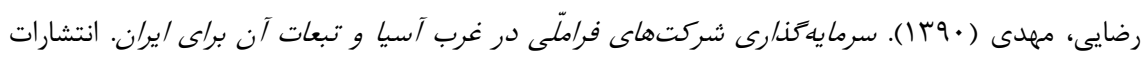

$$
\text { موسسه مطالعات و يزوهش هاى بازر كانى. }
$$

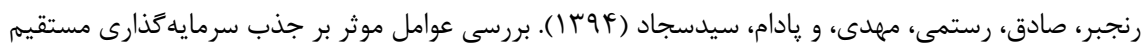

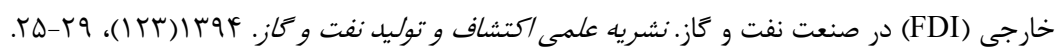

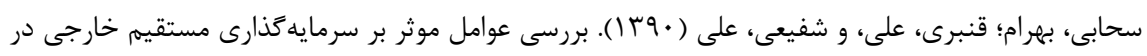

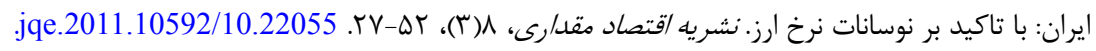

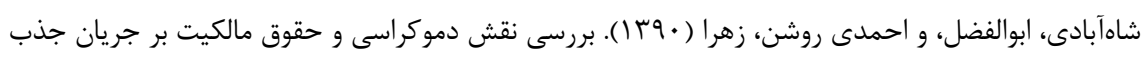

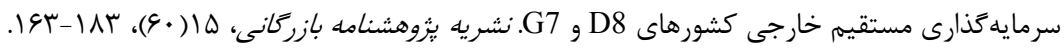

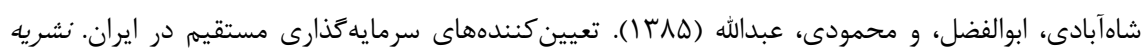

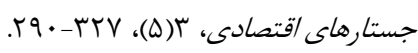

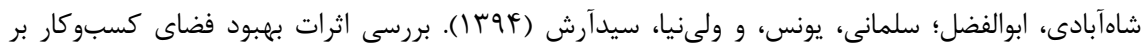

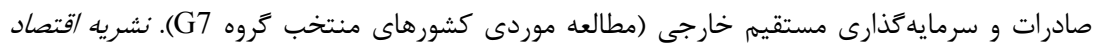

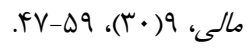

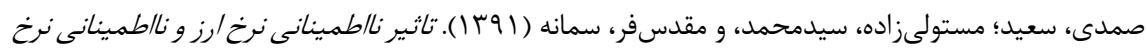

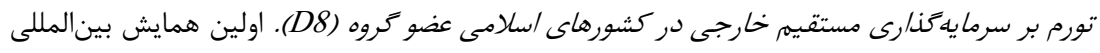

$$
\text { اقتصادسنجى، روشها و كاربردها. }
$$

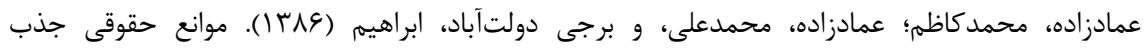

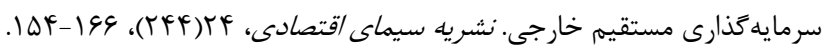

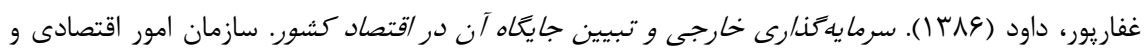


دارايى استان مركزى.

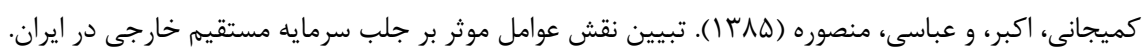

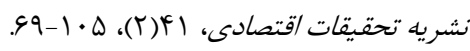

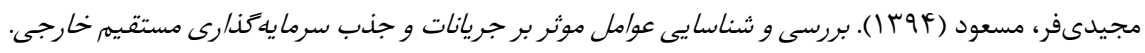

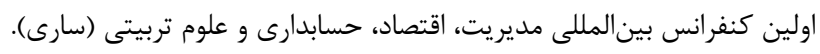

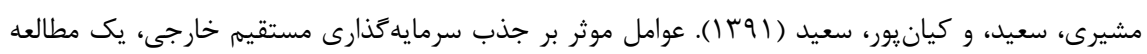

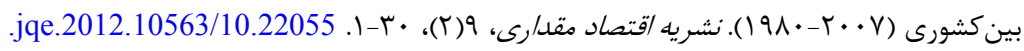

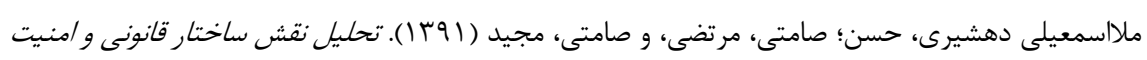

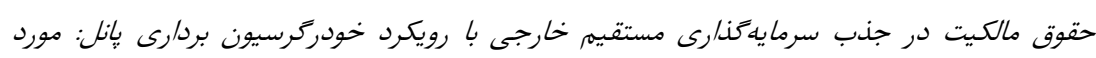

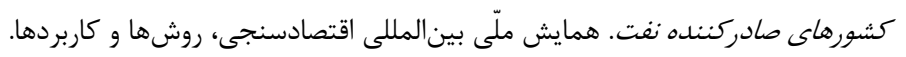

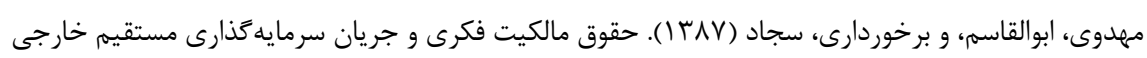

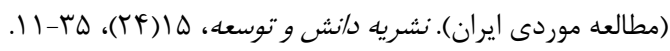

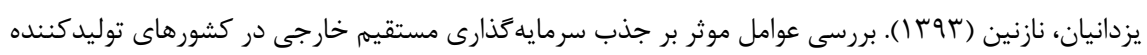

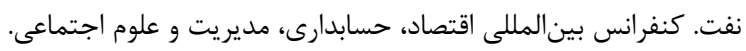

Blonigen, B. A. (2005). A Review of the Empirical Literature on FDI Determinants. Atlantic Economic Journal, 33(4), 383-403. https://doi.org/10.1007/s11293-005-2868-9.

Chakrabarti, A. (2001). The Determinants of Foreign Direct Investments: Sensitivity Analyses of Cross-Country Regressions. Kyklos, 54(1), 89-114. https://doi.org/10.1111/1467-6435.00142.

Chan, M. L., Hou, K., Li, X., \& Mountain, D. C. (2014). Foreign Direct Investment and Its Determinants: A Regional Panel Causality Analysis. The Quarterly Review of Economics and Finance, 54(4), 579-589. https://doi.org/10.1016/j.qref.2013.07.004.

Froot, K. A., \& Stein, J. C. (1991). Exchange Rates and Foreign Direct Investment: An Imperfect Capital Markets Approach. The Quarterly Journal of Economics, 106(4), 1191-1217. https://doi.org/10.2307/2937961.

Mathew, A. J., \& Mukherjee, A. (2014). Intellectual Property Rights, Southern Innovation and Foreign Direct Investment. International Review of Economics \& Finance, 31(1), 128-137. https://doi.org/10.1016/j.iref.2013.11.004.

Moosa, I. A., \& Cardak, B. A. (2006). The Determinants of Foreign Direct Investment: An Extreme Bounds Analysis. Journal of Multinational Financial Management, 16(2), 199-211. https://doi.org/10.1016/j.mulfin.2005.07.002.

Seyoum, B. (1996). The Impact of Intellectual Property Rights on Foreign Direct Investment. The Columbia Journal of World Business, 31(1), 50-59. https://doi.org/10.1016/S002290006-(96)5428X. 
Tanaka, H., \& Iwaisako, T. (2014). Intellectual Property Rights and Foreign Direct Investment: A Welfare Analysis. European Economic Review, 67(1), 107-124. https://doi.org/10.1016/j.euroecorev.2014.01.013.

Ushijima, T.(2013). Patent Rights Protection and Japanese Foreign Direct Investment. Research Policy, 42(3), 738-748. https://doi.org/10.1016/j.respol.2012.09.010. 